\title{
ANALISA KOMPONEN HAMBATAN KAPAL IKAN TRADISIONAL DI PERAIRAN CILACAP
}

\section{RESISTANCE COMPONENT ANALYSIS OF TRADITIONAL FISHING BOAT IN CILACAP}

\section{Samuel}

Teknik Perkapalan, Universitas Diponegoro Semarang

Corresponding author e-mail: undip_samuel@yahoo.com

Received: December 2, 2015/Accepted: March 29, 2016

\begin{abstract}
Monohull fishing boats used to catch fish is modified into a catamaran boat. The purpose of this modification is to get more fish. Catamaran ship has a double hull, but with the double hull ships resulted in increasingly complex resistances. It is interesting to study in depth about the resistance components of Catamaran boat. Resistance Components not only consist of surge resistance, frictional resistance, and the form resistance but with the distance between demihull causing interference waves. There are many research results of Catamaran boat in that aspect, but the data and information obtained from the experiment is still inadequate. In addition, there is still lack of accuracy particularly in predicting interference resistance component in calm water (calm-water resistance) as a result of the distance between the demihull. This study aims to describe the resistance component at Catamaran boat by using slender body method.
\end{abstract}

Keywords: catamaran, Cilacap, slender body method

\section{ABSTRAK}

Kapal ikan monohull yang biasa digunakan untuk mencari ikan dimodifikasi menjadi kapal catamaran. Tujuan modifikasi ini untuk mendapatkan muatan ikan yang lebih banyak. Kapal Catamaran mempunyai dua lambung, tetapi dengan adanya dua lambung mengakibatkan hambatan kapal semakin kompleks. Menarik untuk dikaji lebih lanjut tentang komponen hambatan kapal Catamaran. Komponen hambatan tidak hanya terdiri dari hambatan gelombang, hambatan gesek, dan hambatan bentuk namun dengan adanya jarak antar demihull sehingga menimbulkan interferensi gelombang. Sudah banyak dijumpai hasil riset kapal Catamaran pada aspek tersebut, tetapi data dan informasi yang diperoleh dari eksperimen masih kurang memadai. Disamping itu, masih ditemukan ketidak-akurasian khususnya dalam memprediksi interferensi komponen hambatan pada air tenang (calm-water resistance) akibat dari adanya jarak antar demihull tersebut. Penelitian ini bertujuan untuk memaparkan komponen hambatan pada kapal Catamaran dengan menggunakan slender body method.

Kata kunci: catamaran, Cilacap, slender body method

\section{PENDAHULUAN}

Penelitian tentang hambatan dan propulsi pada lambung kapal Catamaran atau twin hull belakangan ini mengalami peningkatan seiring pesatnya pembangunan kapal Catamaran untuk berbagai aplikasi antara lain fishing boat, ferry, dll. Salah satu hal yang membuat kapal Catamaran menjadi populer dan banyak diaplikasikan karena adanya area geladak (deck area) yang lebih luas dan tingkat stabilitasnya yang lebih nyaman dan aman. Disamping itu kapal Catamaran dengan bentuk badan yang langsing (slender) dapat memperkecil timbulnya sibakan air (wave wash) dibanding kapal monohull (Jamaluddin et al., 2012).

Salah satu aspek yang perlu diperhatikan pada kapal Catamaran adalah keakurasian dalam mengestimasi hambatan pada tahapan awal proses design, dimana hambatan kapal merupakan aspek yang sangat penting diketahui untuk menghitung daya mesin suatu kapal. 
ISSN: 1907-9931 (print), 2476-9991 (online)

Hambatan lambung kapal Catamaran hingga kini masih terus dibahas dan dikaji lebih dalam di berbagai forum ilmiah karena komponen hambatannya lebih kompleks dibanding kapal monohull (satu lambung), yang mana disebabkan rumitnya efek interferensi viskos dan gelombang yang terjadi akibat adanya efek interaksi di antara kedua lambung kapal Catamaran (Insel dan Molland, 1990). Interferensi hambatan yang ditimbulkan oleh kedua lambung kapal tersebut menjadi fenomena yang kompleks dan fenomena tersebut hingga saat ini masih merupakan kajian yang menarik bagi para peneliti kapal multihull.

Penelitian ini ingin mengembangkan pengetahuan perihal karakteristik komponen hambatan yang terjadi pada lambung catamaran terhadap jarak lambung secara melintang menggunakan slender body method.

\section{MATERI DAN METODE}

\section{Slender Body Method}

Slender body method diaplikasikan untuk perhitungan hambatan lambung kapal monohull dan multihull, dengan mengasumsikan kapal berbentuk simetris dan pipih dimana rasio antara panjang dan lebar kapal yang besar $\left(\mathrm{L} / \mathrm{V}^{1 / 3}\right)$. Pada program hullspeed Maxsurf, metode slender Body didasarkan pada penelitian Tuck et al. (1999) dan Couser (1996), dengan menggunakan dasar pendekatan Michell ( Hullspeed User Manual, 2005) untuk menghitung hambatan gelombang dengan bilangan Froude $<10$. Michell mengekspresikan hambatan gelombang dari dinding tipis samping lambung kapal seperti persamaan (1) dan (2).

$$
\begin{aligned}
& R_{W}=\frac{4}{\pi} \rho V^{2} V^{2} \int_{1}^{\infty} \frac{\lambda^{2}}{\sqrt{\lambda^{2}+1}}|A(\lambda)|^{2} d \lambda \\
& A(\lambda)=-i v \lambda \int e^{W \lambda^{2} z+i v \lambda x} f(x, z) d z d x
\end{aligned}
$$

Dimana: $V$ adalah kecepatan kapal, $\rho$ adalah density air, $u=g / V^{2}, g$ adalah gravitasi, $f(x, z)$ setengah dari lebar kapal, $x$ adalah koordinat memanjang (+ kedepan), $z$ adalah koordinat vertikal (dari permukaan air, + keatas) dan $\lambda$ adalah bidang basah kapal dibawah permukaan.

Metode ini menghitung energy pada pola gelombang permukaan bebas yang dihasilkan oleh kapal yang menyebabkan tahanan gelombang kapal untuk menghitung hambatan. Hullspeed menghitung dan menambahkan komponen hambatan viskos dengan menggunakan perhitungan koefisien gesek dan faktor bentuk yang ditentukan ITTC ' 57 . Sedangkan Komponen hambatan kapal Catamaran dinyatakan dengan persamaan 6-12 (Jamaluddin et al., 2012)

\section{Komponen Koefisien Interaksi Hambatan pada kapal Catamaran}

Hambatan kapal Catamaran diasumsikan sebagai penjumlahan dari beberapa komponen hambatan, agar memudahkan dalam pemecahan masalah hambatan kapal pembagian komponen hambatan, secara skematik, diperlihatkan pada Gambar 1.

Kemudian untuk komponen koefisien interaksi hambatan pada demihull (Catamaran) adalah seperti dalam persamaan (3).

$\left(\mathrm{C}_{T}\right)_{C A T}=(1+\phi \mathrm{k}) \sigma C_{F}+T C_{W}$

\section{Dimana:}

$\Phi=$ Faktor interferensi hambatan bentuk (form), yang diakibatkan oleh perubahan tekanan yang terjadi antara dua lambung

$\sigma=$ Faktor interferensi hambatan gesek (friction), yang diakibatkan oleh terjadinya penambahan kecepatan aliran diantara dua lambung.

$\mathrm{T} \quad=$ Faktor interferensi hambatan gelombang (wave), yang diakibatkan oleh pertemuan dua moda gelombang (dari haluan) diantara kedua lambung. 


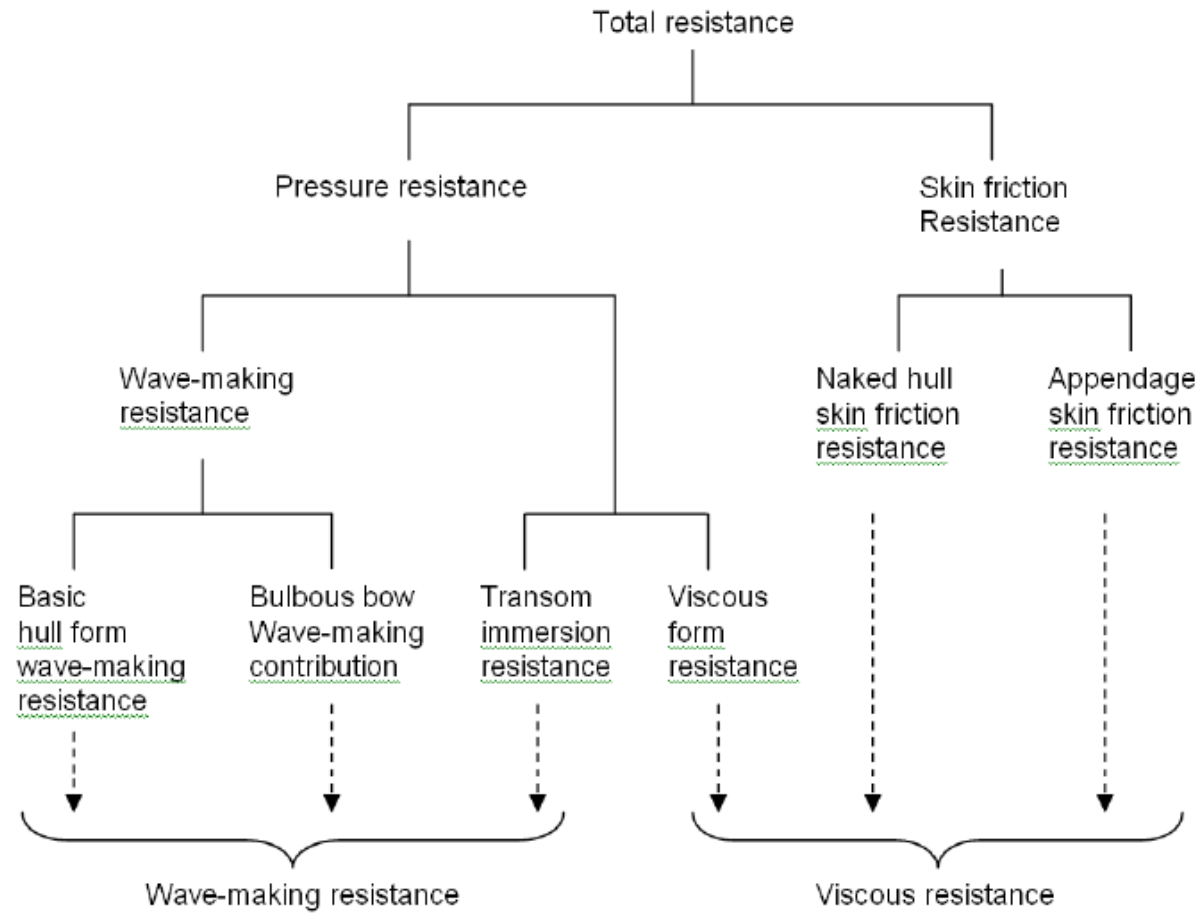

Gambar 1. Diagram komponen hambatan kapal (Molland, 2008).

Diketahui bahwa faktor interferensi $\Phi$ dan $\sigma$ sangat rumit dan kompleks dalam pemecahannya, maka Insel dan Molland (1991) memperkenalkan faktor $\beta$ untuk mengkombinasikan faktor interfensi $\Phi$ dan $\sigma$ ke dalam interferensi hambatan viskos untuk tujuan praktis, menjadi:

$\left(\mathrm{C}_{T}\right)_{C A T}=(1+\beta k) \mathrm{C}_{F}+T \mathrm{CW}_{\mathrm{W}}$

Persamaan (4) tersebut diaplikasikan secara luas untuk perhitungan hambatan lambung Catamaran hingga saat ini.

\section{HASIL DAN PEMBAHASAN}

Perhitungan komponen hambatan lambung Catamaran dengan menggunakan metode form factor $(1+\beta k)$ yang diperkenalkan oleh Molland ( Hullspeed User Manual, 2005)

$(1+\beta k)=3.03\left(L / \mathrm{N}^{1 / 3}\right)^{-0.04}$

Persamaan 5 dikenal dengan "Molland Algorithm", dimana mengekspresikan interaksi dan interferensi viskos pada lambung Catamaran dan digunakan secara luas dalam commercial naval engineering softwere untuk menghitung viscous form factor pada lambumg Catamaran.

Berdasarkan perbedaan antara hasil 'slender body method' yang menggunakan Molland alogarithm dan hasil eksperimen model fisik di Towing Tank, maka perlu memodifikasi 'Molland Algorithm'.

$(1+\beta k)=3.03\left(\mathrm{~L} / \mathrm{V}^{1 / 3)-0.40}+0.016(\mathrm{~S} / \mathrm{L})^{-0.65}\right.$

Persamaan 6 di atas merupakan persamaan yang diberikan oleh Jamaludin et al. (2012), dengan mengaplikasikan persamaan 6 (proposed equation) tersebut, nilai viscous form factor mendekati hasil eksperimen dengan error yang sangat kecil yakni $<0.06 \%$. 
Jamaludin et al. (2012) mengajukan hasil kajian numerik dan eksperimen, faktor interferensi hambatan ( $\mathrm{T}$ ) dapat diketahui bentuk persamaannya (melalui analisa regresi), dimana Interferensi komponen hambatan gelombang bergantung pada Froude number:

$\tau=0.068(\mathrm{~S} / \mathrm{L})^{-1.38}($ pada $\mathrm{Fr}=0.19)$
$\tau=0.359(\mathrm{~S} / \mathrm{L})^{-0.87}($ pada $\mathrm{Fr}=0.28)$
$\tau=0.574(\mathrm{~S} / \mathrm{L})^{-0.33}($ pada $\mathrm{Fr}=0.37)$
$\tau=0.790(\mathrm{~S} / \mathrm{L})^{-0.14}($ pada $\mathrm{Fr}=0.47)$
$\tau=0.504(\mathrm{~S} / \mathrm{L})^{-0.31}($ pada $\mathrm{Fr}=0.56)$
$\tau=0.501(\mathrm{~S} / \mathrm{L})^{-0.18}($ pada $\mathrm{Fr}=0.65)$

\section{Perhitungan Komponen Hambatan pada Demihull (monohul)}

Gambar 2 memperlihatkan hasil perhitungan komponen koefisien hambatan dengan menggunakan metode slenderbody dengan software hullspeed maxsurf, dimana nilai form factor $(1+k)=1,349$.

Gambar 2 memperlihatkan komponen koefisien hambatan (Cw, Cf, Ct) nilai tersebut didapatkan dari software hullspeed-maxsurf dengan dasar pendekatan michell sesuai persamaan 1 dan 2. Koefisien hambatan gesek (Cf) adalah konstan terhadap kecepatan. Sedangkan koefisien hambatan gelombang (Cw) semakin besar dengan bertambahnya kecepatan, dan untuk komponen koefisien hambatan total $(\mathrm{Ct})$ semakin besar.

\section{Perhitungan komponen hambatan pada Lambung Catamaran}

Perhitungan komponen hambatan lambung Catamaran dengan menggunakan metode form factor $(1+\beta k)$ atau persamaan 6 yang diperkenalkan oleh Molland (Hullspeed User Manual, 2005) dan dikembangkan dan dimodifikasi oleh Jamaludin et al. (2012).

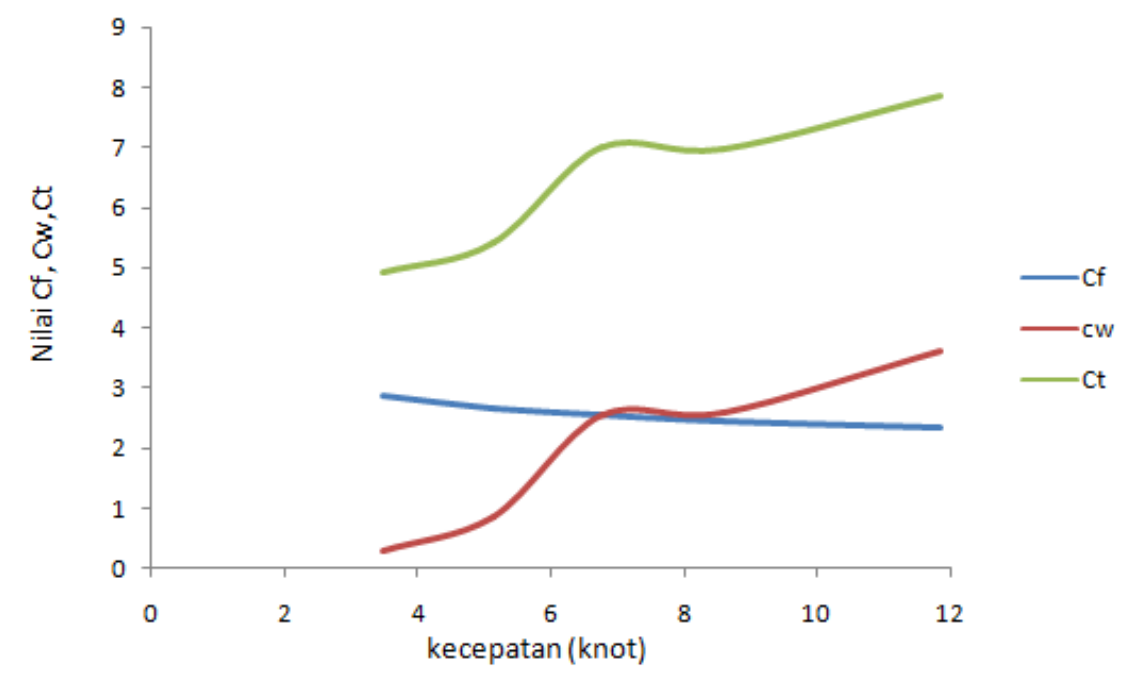

Gambar 2. Komponen koefisien hambatan lambung (demihull). Cf adalah Koefisien hambatan gesek, $\mathrm{Cw}$ adalah koefisien hambatan gelombang dan $\mathrm{Ct}$ adalah koefisien hambatan total. 


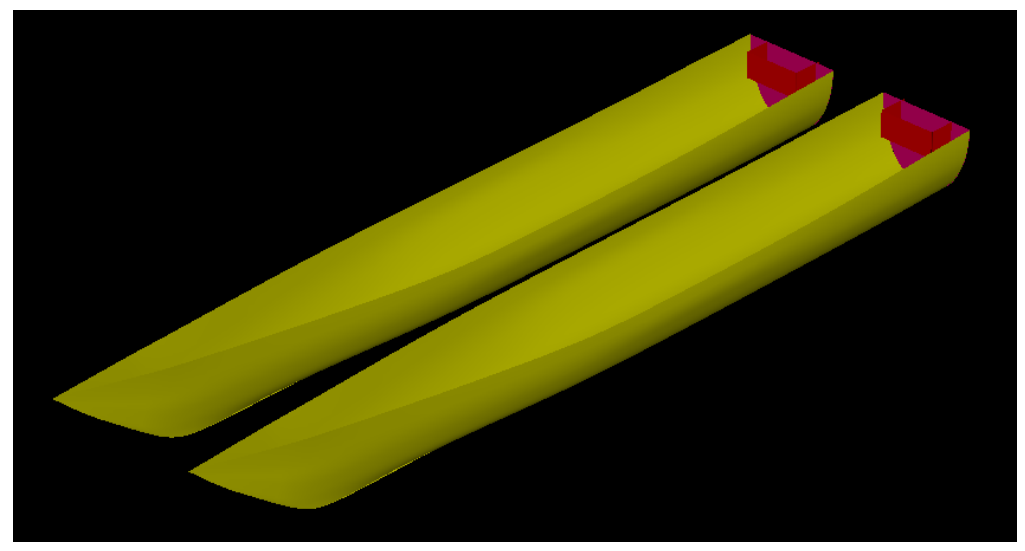

Gambar 3. Desain 3D kapal catamaran

Nilai form factor untuk karakteristik geometri demihull yang diamati adalah $(1+\beta \mathrm{k})=1,61$. Bentuk geometri lambung Catamaran yang simetris disajikan pada tabel 1.

Tabel 1. Ukuran geometri lambung

\begin{tabular}{cc}
\hline Catamaran Hull Form & Symetrical Monohull \\
\hline $\mathrm{Cb}$ & 0,52 \\
$\mathrm{~L} / \mathrm{V}^{1 / 3}$ & 7,53 \\
$\mathrm{~L} / \mathrm{B}$ & 8,09 \\
$\mathrm{~B} / \mathrm{T}$ & 2,2 \\
$\mathrm{~S} / \mathrm{L}$ & 0,2 \\
\hline
\end{tabular}

\section{Komponen hambatan pada Lambung Catamaran}

Dalam perhitungan 'slender body method" pada program "hullspeed-Maxsurf", efek interferensi akibat adanya jarak antara dua lambung (Catamaran) terhadap hambatan gesek (friction) dapat diekspresikan dengan modifikasi $\beta$ pada form factor. Nilai form factor untuk bentuk geometri lambung Catamaran diamati diperoleh:

$$
\begin{array}{ll}
\text { Demihull }(1+\mathrm{k}) & =1,349 \\
\text { Catamaran }(1+\beta k) & =1,61
\end{array}
$$

Nlai form factor diasumsikan konstan terhadap froude number (Fn), sedangkan nilai faktor interferensi gelombang ( $\mathrm{T}$ ) bervariasi sesuai dengan froude number (Fn). Gambar 3 memperlihatkan nilai faktor interferensi hambatan gelombang $(\mathrm{T})$ sesuai dengan froude number (Fn).

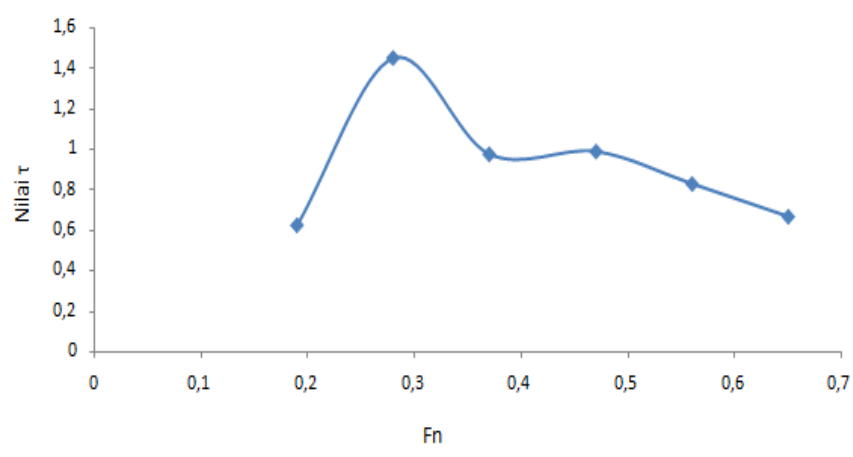

Gambar 4. Faktor interferensi gelombang $(\tau)$ 
Gambar 5 memperlihatkan komponen koefisien hambatan total (Ct) pada lambung kapal Catamaran dengan rasio $S / L$ 0,2.

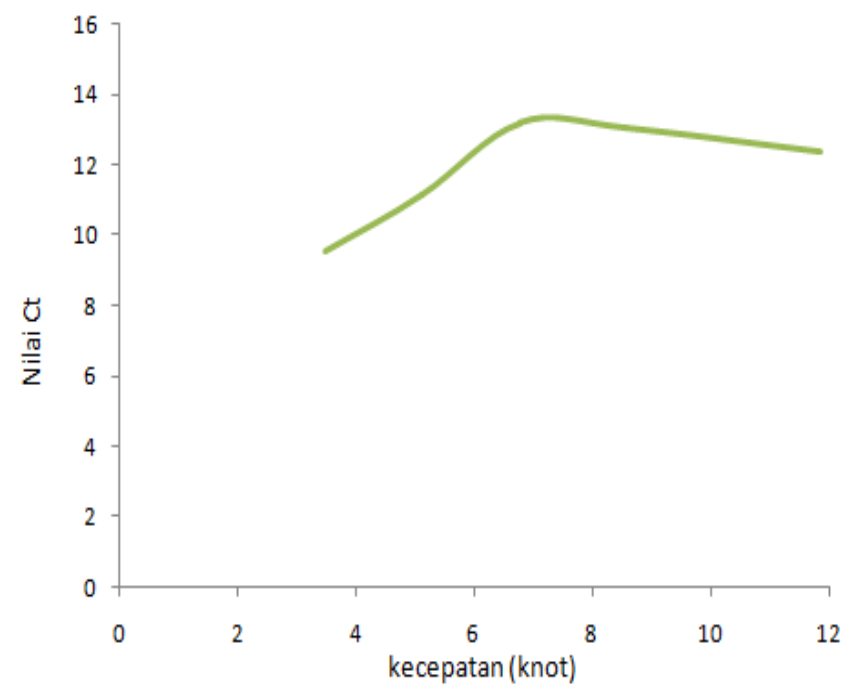

Gambar 5. Koefisien hambatan total

Hasil dari komponen hambatan koefisien hambatan total pada kapal Catamaran lebih besar hampir dua kali lipatnya dari hambatan lambung kapal monohull (demihull). Koefisien hambatan total (Ct) didapatkan dengan persamaan 4 kemudian dikalikan dua untuk mendapatkan $\mathrm{Ct}$ kapal Catamaran. Kemudian hambatan total diperlihatkan pada Gambar 6 yang didapatkan dengan persamaan 13.

$R t=1 / 2 \cdot v^{2} \cdot p \cdot$ WSA.CT

Dimana:

Rt $\quad=$ Hambatan Total $(\mathrm{KN})$

$\mathrm{P}=$ Massa Jenis Air Laut $\left(1025 \mathrm{~kg} / \mathrm{m}^{3}\right)$

$\mathrm{V} \quad=$ Kecepatan Kapal $(\mathrm{m} / \mathrm{s})$

WSA = Luas permukaan kapal Catamaran yang tercelup air $\left(\mathrm{m}^{2}\right)$

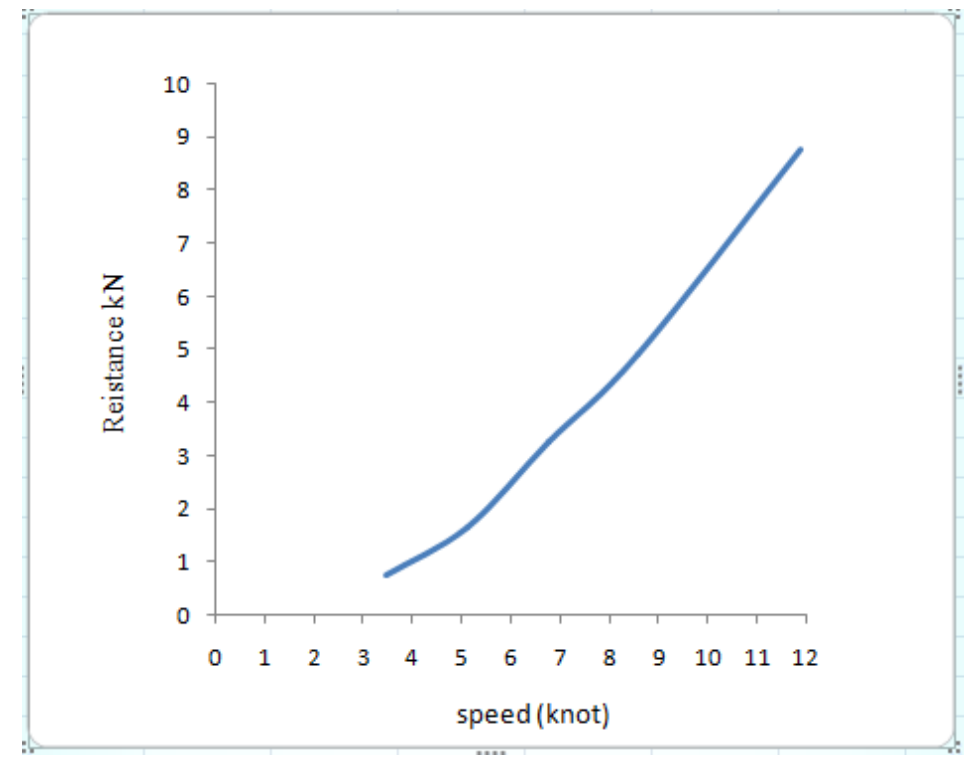




\section{Gambar 6. Hambatan total (RT)}

Pada gambar 6 memperlihatkan grafik dari nilai hambatan total kapal Catamaran dengan pengaruh interferensi gelombang, dapat dilihat dari grafik tersebut bahwa hambatan total (Rt) semakin besar dengan bertambahnya kecepatan.

\section{KESIMPULAN DAN SARAN}

Dari hasil perhitungan menggunakan 'slender body method' untuk mengkaji komponen interferensi hambatan padalambung Catamaran, maka dapat disimpulkan bahwa koefisien hambatan gesek (Cf) selalu konstan terhadap kecepatan sedangkan koefisien hambatan gelombang $(\mathrm{Cw})$ semakin besar dengan bertambahnya kecepatan. Sehingga koefisien hambatan total pada kapal Catamaran lebih besar hampir dua kali lipatnya dari koefisien hambatan total lambung kapal monohull (demihull), hal ini dikarenakan adanya hambatan gesek pada dua lambung (catamaran) ditambahkan efek dari interferensi gelombang.

\section{DAFTAR PUSTAKA}

Jamaluddin, A., Utama, I., Widodo, B., \& Molland, A. (2012). Experimental and numerical study of the resistance component interactions of catamarans. Proceedings of the Institution of Mechanical Engineers, Part M: Journal of Engineering for the Maritime Environment, 227(1), 51-60. http://doi.org/10.1177/1475090212451694

Insel, M. (1990). An investigation into the resistance components of high speed displacement catamarans. PhD Thesis, Faculty of Engineering and Applied Science, University of Southampton, U.K.

Tuck, E. O., Luzauskas, L., \& Scullen, D. C. (1999). Sea wave pattern evaluation. Part 1, report primary code and test results (surface vessels). Applied Mathematics Department, The University of Adelaide. $\quad 30$ April 1999 also available from: http://www.c yberiad.net/library/pdf/tls99.pdf (January 2005)

Couser, P. (1996). An investigation into the performance of high-speed catamarans in calm water and waves. PhD thesis, Department of Ship Science, University of Southampton

Hullspeed User Manual (2005). Hullspeed-Maxsurf, Formation Design Systems Pty Ltd 1984 2006

Molland, A. F. (2008). A guide to ship design, construction and operation. The Maritime Engineering Reference Book, Butterworth- Heinemann, Elsevier.

Insel, M., \& Molland, A. F. (1991). An investigation into the resistance components of high speed displacement catamaran. Royal Institution of Naval Architects, Spring Meeting, paper No. 11. 